\title{
Insecticide-treated net ownership and utilization and factors that influence their use in Itang, Gambella region, Ethiopia: cross-sectional study
}

This article was published in the following Dove Press journal:

Risk Management and Healthcare Policy

31 May 2016

Number of times this article has been viewed

\author{
Aklilu Habte Watiro' \\ Worku Awoke ${ }^{2}$ \\ 'Médecins Sans Frontières OCA \\ (MSF Holland) Ethiopia Mission, Addis \\ Ababa, ${ }^{2}$ Department of Epidemiology, \\ School of Public Health, College of \\ Medicine and Health Sciences, Bahir \\ Dar University, Bahir Dar, Ethiopia
}

Correspondence: Aklilu Habte Watiro PO Box 34357, Yeka, Addis Ababa, Ethiopia

Tel +25l 9l 3180806

Email akwal.2000@gmail.com
Background: Malaria remains a major public health problem in Ethiopia. Consequently, Ethiopia designed the 2011-2015, Malaria Prevention and Control Strategic Plan to fight the vector. It was discovered that most of the studies conducted on the use of insecticide-treated nets (ITNs) were not in line with the strategic plan of the country. This study aimed to assess ITN ownership and utilization, and includes barriers related to its use among the target-area population at household $(\mathrm{HH})$ level.

Materials and methods: A cross-sectional design was employed in Itang for this study. Data were collected by trained nurses through face-to-face interview and observation. A total of 845 participants were selected through multistage sampling, and the size was determined by using a single-population proportion formula. EPI Info and SPSS was used for analysis, and all necessary statistical association was computed in order to explain the outcome variable through explanatory variables of this study.

Results: Among $845 \mathrm{HHs}$ interviewed, 81.7\% (690) had at least one ITN, while $52.3 \%$ (361) had used the ITN the night preceding the data-collection day. HH awareness of malaria prevention, number of ITNs, family size, number of family members sharing sleeping area/beds, sleeping patterns of adolescents, HH-head age, and inconvenience of using ITNs were found to be barriers to the use of ITNs in this study.

Conclusion and recommendation: The study concluded that very few HHs owned ITNs and there was very low usage of ITNs. In recommendation, the regional health bureau and district health office should consider bigger nets that can accommodate family members who share the same sleeping area/bed in the area.

Keywords: consistent use, household, insecticide-treated nets, Itang, ownership, utilization

\section{Background}

Remarkable implementations of different integrated vector-control strategies throughout the world have shown a progressive impact on the improvement of malaria morbidity and mortality; ${ }^{1}$ however, malaria is still a major public health problem. ${ }^{2,3}$ Over 2 billion people worldwide are estimated to be exposed to malaria infection, and according to the World Health Organization's World Malaria Report 2014, 198 million estimated cases of malaria were reported in the year 2013 with 584,000 deaths, of which 453,000 were children under the age of 5 years. ${ }^{2}$ Malaria continues to be an overwhelming public health problem in Africa, especially the sub-Saharan countries, with $90 \%$ of annual world malaria cases in the region., ${ }^{2,4}$ Transmission of malaria in this region is the highest in the world, and children, pregnant women, and poor families are the most vulnerable groups. ${ }^{4,5}$ 
Malaria remains the leading public health problem in Ethiopia. ${ }^{1,5,6}$ The problem covers $75 \%$ of the landmass of the country, and $68 \%$ of the population are living in malaria-risk areas. ${ }^{3,6-8}$ In spite of this, the Ministry of Health in Ethiopia designed a 5-year (2011-2015) malaria-prevention and -control strategic plan to fight the vector by using indoor residual spray (IRS) and long-lasting (LL) insecticide-treated nets (ITNs) as a main tool for program implementation, in line with early case detection and treatment with a strong surveillance system by using the existing health system of the country. The country planned to cover $90 \%$ of malarial areas with IRS in 2013-2015, to cover 100\% of households (HHs) of malaria-endemic areas with one LL ITN (LLIN) per sleeping space, and to reach at least $80 \%$ consistent LLIN utilization status. Overall, with an aim of attaining the Roll Back Malaria (RBM) target in Ethiopia, 20 million ITNs were distributed between 2005 and 2007. In addition to this, the country distributed more than 15 million LLINs in 2010 and 2011 to replace previously distributed nets. ${ }^{8}$

Unlike other regions of Ethiopia, the Itang District study area is known to be in a stable form of malaria transmission in most parts of the region and flooded throughout rain seasons. ${ }^{9}$ Intensive research and development on impregnated mosquito nets that would remain effective over a longer period without need of reimpregnation ${ }^{5}$ has been going on. LLINs were adopted as the safest and most successful, effective, and preventive measures against malaria through their barrier and knockdown effect. ${ }^{10,11}$ Nonetheless, their intended impact cannot be realized without consistent use by the majority $(80 \%)$ of the population. ${ }^{12}$

Different studies conducted in the country and parts of the world have shown that there were improvements on ITN ownership, whereas regarding utilization at $\mathrm{HH}$ level, there are a lot of ups and downs. ., $, 7-10,13-27$ Evidence extracted from different studies showed the utilization status of ITNs was affected by different factors - geographical, individual, $\mathrm{HH}$, and environmental - among ITN owners: the HH residence, ${ }^{16}$ literacy level of the $\mathrm{HH},{ }^{3,17}$ awareness of ITNs, ${ }^{17}$ geographical settlement of the $\mathrm{HH},{ }^{3,10}$ number of sleeping rooms in the $\mathrm{HH}$, individual ITN-color preference, presence of children aged under 5 years in the HH, IRS status of the $\mathrm{HH}$, awareness of malaria prevention, ${ }^{10} \mathrm{HH}$-head sex, $\mathrm{HH}-$ head income, availability of radio, ${ }^{3}$ duration of ITNs received by the $\mathrm{HH}$, family size of the $\mathrm{HH}$, and occupational status of the HH head. ${ }^{15}$

Small- and large-scale community trials conducted in different parts of the world have shown proper utilization of ITNs is the most cost-effective method for reducing malaria morbidity and mortality in malaria-endemic areas of the world, Ethiopia included. ${ }^{1,5,11,16}$ Different research metaanalysis showed that the introduction of ITNs plays a huge role in malaria and some vector-borne disease reduction in the country, as well as in the world at large, resulting in malaria losing its leading position in the top ten morbidities to other infectious diseases in malaria-endemic areas of the country. ${ }^{5,16,27}$ Ironically, malaria remains the leading morbidity in the Itang district of the Gambella region, despite the 2011 nationwide Malaria Indicator Survey showing ITN utilization in children and pregnant women being the highest, with lower malaria prevalence compared to other regions. This study questioned why the Malaria Indicator Survey report was against the District Health Office unpublished 2014/15 fiscal year report that shows malaria is the leading cause of morbidity.

In fact, many studies have been conducted in the country on ITN use and its associated factors. ${ }^{3,6,10,11,14,17,18,20}$ According to these study findings, barriers to use ITNs were different from place to place, with very few similarities. Also, no one had tested whether these factors really affect ITN use in this study area, with its unique paradox of stable form of malaria transmission.

Therefore, this study aimed to assess ownership and utilization of ITNs in 2015 with factors that influenced their use in Itang, Gambella, Ethiopia. It is intended to provide appropriate evidence linked to ITN use, in order to design appropriate prevention and control strategies for the district, as well as contribute to national malaria-prevention andcontrol policy development.

\section{Materials and methods \\ Study area}

Gambella is one of nine regional states of Ethiopia, located approximately $720 \mathrm{~km}$ southwest of Addis Ababa. Most of the region is flat, hot, and humid, with an altitude range of 300-2,000 $\mathrm{m}$ above sea level and sloping westward. The annual average temperature of the region is $21.1^{\circ} \mathrm{C}-35.9^{\circ} \mathrm{C}$, with an average annual rainfall of $600 \mathrm{~mm}$. Itang is one of among 15 districts of Gambella, and is situated $42 \mathrm{~km}$ to the west of the regional capital of Gambella. The district has 23 precinct organizations (kebele), with a current total population of 45,772 and 9,154 HHs. The district's average annual temperature and rainfall are $29^{\circ} \mathrm{C}$ and $1,000 \mathrm{~mm}$, respectively. District climatic conditions are favorable for the existence of a stable form of malaria throughout the year. ${ }^{9}$ According to a 2006 (Ethiopian calendar) fiscal year district health office report, the district has three health centers and six health 
posts, though 22 kebele were covered by two health-extension workers in each kebele.

\section{Study design and population}

A cross-sectional quantitative study was conducted at $\mathrm{HH}$ level in Itang, Gambella, Ethiopia from March 25 to April 12, 2015. All HHs in Itang were the source population of this study, and randomly selected HHs after multistage sampling were study participants.

\section{Sample-size determination and sampling}

For sample-size determination, a single-population proportion formula with a $95 \%$ level of confidence $\left(n=Z^{2} p \times q / w^{2}\right)$, design effect of 2 for multistage sampling, and $10 \%$ nonresponse rate were used. Study findings considered for samplesize determination were ITN ownership of $69.3 \%$, utilization of $64.9 \%$, and consistent use of $51 \%$ in Gida Ayana, East Welega, Ethiopia, ${ }^{16} 2011$ Malaria Indicator Survey Gambella ITN utilization of $83.6 \%$ and $53 \%$ among children aged under 5 years and pregnant women, respectively, ${ }^{7}$ and the $60.4 \%$ of HHs that lack access to the nearest health facility in the southwest of Ethiopia. ${ }^{18}$ Finally, the highest sample size was taken as the minimum sample size adequate for generalizing findings for the source population. As shown in Table 1, the sample with 845 participants was selected as the minimum sample size for this study. All 23 kebele (the smallest administrative unit in Ethiopia) of the district were listed, and $20 \%$ of the kebele (five kebele with a total of $4,160 \mathrm{HHs}$ ) were selected by a lottery method. Through this process, Achewa, Baziel, Itang Kir, Pukumu, and Pulkode kebele were selected for this study. Then, in order to get a sampling frame, all of the selected kebele villages were listed, and 30\% (35 villages with a total of 1,248 HHs) were selected by a lottery method. At this stage, a sampling frame existed with family folders at the kebele level. HHs in these villages

Table I Sample sizes considered to decide the number of study participants for ITN ownership and utilization and factors associated with ITN use in Itang district, Gambella region, Ethiopia, 2015

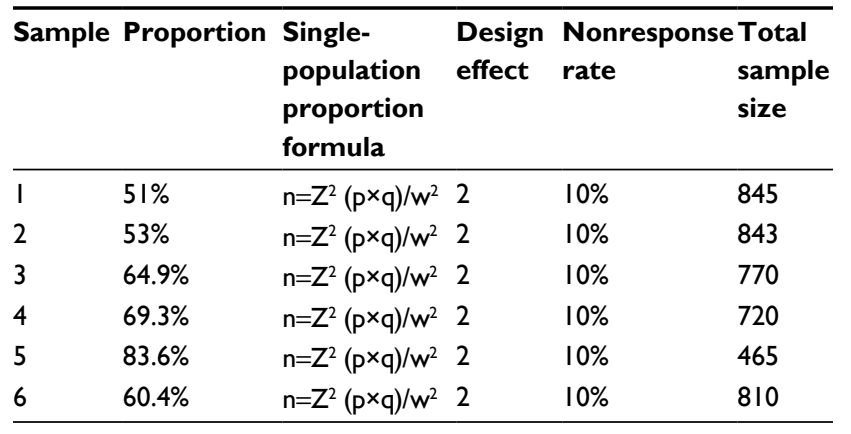

Abbreviation: ITN, insecticide-treated net. were selected with a simple random-sampling technique for this study. According to this, 175, 152, 169, 171, and 178 HHs were selected from Achewa, Baziel, Itang Kir, Pukumu, and Pulkode kebele, respectively.

Randomly selected $\mathrm{HH}$ heads or any member of the $\mathrm{HH}$ over 18 years who could provide credible information were included in this study. At the planning phase of this study, $\mathrm{HH}$ heads and persons severely sick, unable to respond, or not available in their homes for three consecutive visits plus one more final visit at the end of the data-collection period were excluded from this study.

\section{Variables and operational definitions}

ITN-utilization status was the dependent variable of this study. Independent variables were categorized as socioeconomic, topographic, health system-, and ITN-related factors. Variables used in this study was defined operationally to make them measurable:

- HH fully covered by ITNs - an HH with an ITN for each and every sleeping area/beds and observed by enumerators during data collection ${ }^{8}$

- ITN ownership - HHs with one or more ITNs per $\mathrm{HH}^{3,7,8}$

- utilization - refers to HHs that owned an ITN in which one or more members of the HH slept under a net, reportedly or confirmed through observation by enumerators during the early morning preceding this study. 3,10

\section{Data-collection procedure}

A standardized structured questionnaire was used to collect the data, with a few adjustments that would fit with the scope of this study. The questionnaire was prepared originally in English and translated to Amharic. Data were collected by a combination of face-to-face interviews and observation.

The data were collected by five trained nurses during an early morning session. ITN utilization was cross-checked with the interview response of HHs, through direct observation of the enumerators. They checked to confirm that HH ITNs were really utilized/hung up just above sleeping beds/areas or not. Two supervisors who were skilled in the malaria-prevention and -control program of the district health office were assigned to supervise the data-collection process and quality assurance. The data collectors and supervisors were trained for 2 days by the principal investigator. The data collectors practiced for a day at the field level to familiarize themselves with the data tools. To ensure the quality of the questionnaire, the questioner was pretested on $20 \mathrm{HHs}$ of neighboring villages. After this pretest, some adjustments to some variables were made to make it more 
measurable by the respondent. Supervision was conducted by two supervisors and the principal investigator. Every day, collected data were cross-checked, and HHs found vacant/ empty at the first visit were given a chance for a second and third time, including one final visit at the end of the datacollection period.

\section{Data processing and analysis}

Data were entered into the EPI Info computer program to minimize data-entry error. Entered data were then exported to SPSS version 20 (IBM Corporation, Armonk, NY, USA) for analysis, which had to be recoded, categorized, and sorted to facilitate the analysis. The data were described using percentages and distributions of the respondents by sociodemographic characteristics and other relevant variables in the study.

Logistic regression was employed to identify factors associated with ITN use among the study participants. All explanatory variables associated with the outcome variable in bivariate analysis with $P$-values of $\leq 0.15$ for ITN use were included in multivariable analysis. Backward-stepwise binary logistic regression models of multivariable analysis were employed in order to control confounders and the problem of multicollinearity. Hosmer-Lemeshow goodness-of-fit statistics were checked to assess whether the necessary assumptions for the application of multiple logistic regressions were fulfilled, with a $P>0.05$. Variables that showed significant association with the outcome variable in backward-stepwise regression were selected as a full model of outcome-variable predictors if all of the assumptions were fulfilled. Finally, the crude odds ratio (COR) and adjusted OR (AOR), together with their corresponding 95\% confidence intervals (CIs), were computed. $P<0.05$ was considered statistically significant in this study.

\section{Ethical considerations}

Ethical clearance was obtained from Debre Markos University and Gamby College of Medical Science, following an official letter from the regional health bureau to the district through hierarchical levels of communication in the Itang District Health Office. The district health office then wrote a letter permitting each of the kebele in the studied area to be included in this study. Additionally, data collectors explained the purpose of the study to participants of this study, who in turn gave verbal consent for their participation. Reliability and confidentiality of responses were ensured throughout the research process. Finally, data collectors demonstrated the appropriate use of ITNs for HHs that had no knowledge of how to use them.

\section{Results}

\section{Sociodemographic and subject characteristics}

In this study, 845 HHs were included, with a 100\% (845) response rate. Table 2 shows the proportion of HHs with pregnant women and children under 5 years, with $227(26.9 \%)$ and $298(35.3 \%)$, respectively. The average family size of the studied area was 5.5, while nearly half of the HHs had a family size of six and above $-49.5 \%$ (418). Among the studied participants, 79.6\% (673) were rural residents and 20.4\% (172) urban. A high proportion of $82.8 \%$ (700) of HHs were maleheaded, and $37 \%$ (313) of $\mathrm{HH}$ heads were in the age-group 30-39 years. Among the studied HHs, 26.6\% (225) of the $\mathrm{HH}$ heads were unable to read or write, while $28 \%$ (237) of $\mathrm{HH}$

Table $2 \mathrm{HH}$ sociodemographic characteristics of study variables in Itang district, Gambella region, Ethiopia, 2015

\begin{tabular}{|c|c|c|c|}
\hline Variables & Categories & Frequency & Percentage \\
\hline \multirow[t]{5}{*}{ HH-head age } & $<30$ years & 166 & 19.6 \\
\hline & $30-39$ years & 313 & 37 \\
\hline & $40-49$ years & 238 & 28.2 \\
\hline & 50-59 years & 114 & 13.5 \\
\hline & $\geq 60$ years & 14 & 1.7 \\
\hline Pregnant women & Yes & 227 & 26.9 \\
\hline in the $\mathrm{HH}$ & No & 618 & 73.1 \\
\hline \multirow[t]{2}{*}{$\mathrm{HH}$ residence } & Urban & 172 & 20.4 \\
\hline & Rural & 673 & 79.6 \\
\hline \multirow[t]{2}{*}{ Sex of $\mathrm{HH}$ head } & Female & 145 & 17.2 \\
\hline & Male & 700 & 82.8 \\
\hline Educational & Cannot write or read & 225 & 26.6 \\
\hline status of & Able to write and read & 237 & 28 \\
\hline \multirow[t]{3}{*}{$\mathrm{HH}$ head } & Elementary level (I-8) & 153 & 18.1 \\
\hline & High school level (9-12) & 132 & 15.6 \\
\hline & $\begin{array}{l}\text { Higher education } \\
\text { completed }\end{array}$ & 98 & 11.6 \\
\hline $\mathrm{HH}$-head marital & Single & 46 & 5.4 \\
\hline \multirow[t]{3}{*}{ status } & Married & 674 & 79.8 \\
\hline & Divorced & 60 & 7.1 \\
\hline & Widowed & 65 & 7.7 \\
\hline HH-head & Farmer & 432 & 51.1 \\
\hline occupational & Fisherman & 119 & 14.1 \\
\hline \multirow[t]{4}{*}{ status } & Housewife & 55 & 6.5 \\
\hline & Merchant & 102 & 12.1 \\
\hline & Pastoralist & 97 & 11.5 \\
\hline & Others & 40 & 4.7 \\
\hline Children & Yes & 298 & 35.3 \\
\hline$<5$ years old & No & 547 & 64.7 \\
\hline \multirow[t]{4}{*}{ HH family size } & $1-2$ & 180 & 21.3 \\
\hline & $3-5$ & 247 & 29.2 \\
\hline & $6-7$ & 258 & 30.5 \\
\hline & 8 and above & 160 & 19 \\
\hline \multirow[t]{3}{*}{$\mathrm{HH}$ income } & Low income & 785 & 92.9 \\
\hline & High income & 20 & 2.4 \\
\hline & Middle income & 40 & 4.7 \\
\hline
\end{tabular}

Abbreviation: $\mathrm{HH}$, household. 
heads were able to write and read. As Table 3 shows, among the studied HHs, $23.7 \%$ (200) were living in corrugated-iron houses, while a majority $(60.8 \%$ [514]) had a single sleeping room. In addition, 39.4\% (333) of $\mathrm{HH}$ family members shared a single bed or sleeping area with three to five family members of the same HH. As seen in Table 4, 65.8\% (556) of respondents had awareness of malaria prevention, while $77.8 \%$ (657) knew malaria could be transmitted from person to person through mosquito bites. Among HHs with awareness of malaria prevention, the highest proportion $-78.1 \%$ (434) - got information from either health professionals or health extension workers, whereas $21.9 \%$ (122) got it from community health workers. Of the total studied population, $77.4 \%$ (654) of the HHs were found nearer to the health facility and $65.3 \%$ (552) had access to a health facility.

Table 3 Sleeping habits and housing conditions of study participants in Itang district, Gambella region, Ethiopia, 2015

\begin{tabular}{|c|c|c|c|}
\hline Variables & Categories & Frequency & Percentage \\
\hline \multirow[t]{2}{*}{ Separate kitchen } & Yes & 288 & 34.1 \\
\hline & No & 557 & 65.9 \\
\hline $\begin{array}{l}\text { House-roof } \\
\text { construction }\end{array}$ & $\begin{array}{l}\text { Thatch/leaf and all } \\
\text { others }\end{array}$ & 645 & 76.3 \\
\hline material & Corrugated iron & 200 & 23.7 \\
\hline \multirow[t]{3}{*}{ Sleeping rooms } & One & 514 & 60.8 \\
\hline & Two & 178 & 21.1 \\
\hline & Three and above & 153 & 18.1 \\
\hline Beds/sleeping area & One & $15 \mid$ & 17.9 \\
\hline \multirow[t]{3}{*}{ available in the $\mathrm{HH}$} & Two & 398 & 47.1 \\
\hline & Three & 212 & 25.1 \\
\hline & Four and above & 84 & 9.9 \\
\hline HH habit toward & Yes & 721 & 85.3 \\
\hline $\begin{array}{l}\text { sharing one bed/ } \\
\text { sleeping area }\end{array}$ & No & 124 & 14.7 \\
\hline $\begin{array}{l}\text { Sleeping pattern of } \\
\text { children }<5 \text { years old }\end{array}$ & $\begin{array}{l}\text { All children under } 5 \\
\text { years together }\end{array}$ & 64 & 21.5 \\
\hline \multirow[t]{2}{*}{ (298) } & $\begin{array}{l}\text { They sleep with their } \\
\text { mother }\end{array}$ & 42 & 14.1 \\
\hline & $\begin{array}{l}\text { They sleep with both } \\
\text { parents and one } \\
\text { another }\end{array}$ & 192 & 64.4 \\
\hline $\begin{array}{l}\text { Sleeping pattern of } \\
\text { children 5-10 years }\end{array}$ & $\begin{array}{l}\text { Everybody sleeps } \\
\text { alone }\end{array}$ & 94 & 22.1 \\
\hline \multirow[t]{2}{*}{ old (426) } & $\begin{array}{l}\text { All males together or } \\
\text { all females together }\end{array}$ & 185 & 43.4 \\
\hline & $\begin{array}{l}\text { All males and females } \\
\text { together }\end{array}$ & 147 & 34.5 \\
\hline \multirow[t]{3}{*}{$\begin{array}{l}\text { Sleeping pattern of } \\
\text { adolescents }\end{array}$} & $\begin{array}{l}\text { Everybody sleeps } \\
\text { alone }\end{array}$ & 162 & 33 \\
\hline & $\begin{array}{l}\text { All males together or } \\
\text { all females together }\end{array}$ & 246 & 50.1 \\
\hline & $\begin{array}{l}\text { Both males and } \\
\text { females together }\end{array}$ & 83 & 16.9 \\
\hline \multirow{3}{*}{$\begin{array}{l}\text { Persons sharing one } \\
\text { bed }\end{array}$} & $\mathrm{I}-2$ & 275 & 32.5 \\
\hline & $3-5$ & 333 & 39.4 \\
\hline & 6-7 and 8+ & 237 & 28 \\
\hline
\end{tabular}

Abbreviation: $\mathrm{HH}$, household.

\section{ITN ownership}

As per Table 5, 81.7\% (690) of the HHs had at least one ITN compared to $38 \%$ (262) that had two ITNs and the remaining $30.4 \%$ (210) three ITNs. Moreover, 90\% (621) of HHs were able to recognize well whether the ITN was factory-treated, and had LLINs. Notwithstanding family size, average ITN ownership for an $\mathrm{HH}$ was 1.6 in this study area. Of 1,344 total ITNs reported and observed by enumerators, $44.87 \%$ (603) were in good condition, while $32.5 \%$ were in poor condition that allowed insertion of one thumb or more. In spite of this, only $28.41 \%$ (196) HHs were fully covered with ITNs according to the family size of the studied area. In addition, $12.3 \%$ (104) had purchased the ITNs from the market at least once and $50.2 \%$ (424) were willing to buy ITNs if they were available at an affordable price, while $54.6 \%$ were willing to buy if they were cheaper than the mean price of 34.6 Ethiopian Birr (ETB). ITN ownership was higher in rural dwellings (76.3\% [526]) than urban (23.7\% [164]). In addition to this, ITN ownership proportion were higher in male-headed HHs $82 \%$ (566) than that of female-headed HHs $18 \%$. Most of $96.8 \%$ (668) ITNs were owned through government distribution scheme. Most were of the PermaNet 2.0 brand, and among observed ITNs in this study, 89.9\% were obtained within 3 years.

\section{Utilization of ITNs}

As shown in Table 6, among 690 HHs with one or more ITNs, $52.3 \%$ (361) slept under ITNs the night prior to data collection, while ITN use was only $42.7 \%$ among the overall HHs of the study area, including 51.4\% (94) and 56.0\% (135) use

Table $4 \mathrm{HH}$ characteristics related to source of information about ITNs and accessibility of health facilities in Itang district, Gambella region, Ethiopia, 2015

\begin{tabular}{llll}
\hline Variables & Categories & Frequency & Percentage \\
\hline Awareness about & Yes & 556 & 65.8 \\
malaria preventability & No & 289 & 34.2 \\
Believe mosquitoes & Yes & 657 & 77.8 \\
can transmit malaria & No and do not & 188 & 22.2 \\
& know & & \\
Know ITNs can & Yes & 571 & 67.6 \\
prevent malaria & No & 274 & 32.4 \\
Source of & Health professionals 434 & 78.1 \\
information (556) & or HEWS & & \\
& Community & 122 & 21.9 \\
& health workers & & \\
HH distance from & Near & 654 & 77.4 \\
the HC & Far & 191 & 22.6 \\
Accessibility of & Yes & 552 & 65.3 \\
transportation & No & 293 & 34.7 \\
\hline A
\end{tabular}

Abbreviations: $\mathrm{HH}$, household; ITNs, insecticide-treated nets; HEWS, health extension workers; $\mathrm{HC}$, health center. 
Table $5 \mathrm{HH}$ characteristics related to ITN ownership and condition in Itang district, Gambella region, Ethiopia, 2015

\begin{tabular}{|c|c|c|c|}
\hline Variables & Categories & Frequency & Percentage \\
\hline \multirow[t]{2}{*}{ One or more ITNs } & Yes & 690 & 81.7 \\
\hline & No & 155 & 18.3 \\
\hline Number of ITNs per & One & 218 & 31.6 \\
\hline \multirow[t]{2}{*}{$\mathrm{HH}(690)$} & Two & 262 & 38 \\
\hline & Three & 210 & 30.4 \\
\hline $\mathrm{HH}$ fully covered by & Yes & 196 & 28.4 \\
\hline ITNs $(690)$ & No & 494 & 71.6 \\
\hline ITN shape $\mathrm{HH}$ prefers & Rectangular & 349 & 41.3 \\
\hline to use & Conical & 496 & 58.7 \\
\hline Color preference of & Blue & 496 & 58.7 \\
\hline \multirow[t]{2}{*}{$\mathrm{HH}$} & White & 294 & 34.8 \\
\hline & Others & 55 & 6.5 \\
\hline \multirow{4}{*}{$\begin{array}{l}\text { HH period with ITNs } \\
(690)\end{array}$} & Less than or equal & 229 & 33.2 \\
\hline & to 6 months & & \\
\hline & $\mathrm{I}-3$ years & 361 & 52.3 \\
\hline & $3-5$ years and above & 100 & 14.5 \\
\hline \multirow{5}{*}{$\begin{array}{l}\text { Observed brand of } \\
\text { ITNs }(690)\end{array}$} & PermaNet 2.0 & 483 & 70 \\
\hline & Durant & 19 & 2.8 \\
\hline & Interceptor & 61 & 8.8 \\
\hline & Olyset Plus & 51 & 7.4 \\
\hline & All others & 76 & 11 \\
\hline \multirow[t]{2}{*}{ ITN condition $(I, 344)$} & Good & 603 & 44.9 \\
\hline & Poor & 741 & 55.1 \\
\hline \multirow[t]{2}{*}{ Source of ITNs (690) } & All other sources & 22 & 3.2 \\
\hline & $\begin{array}{l}\text { Government } \\
\text { distribution scheme }\end{array}$ & 668 & 96.8 \\
\hline $\mathrm{HH}$ had ever & Yes & 104 & 12.3 \\
\hline purchased ITNs & No & 741 & 87.7 \\
\hline ITNs factory-treated & Yes & 621 & 90 \\
\hline $\begin{array}{l}\text { with insecticide when } \\
\text { obtained }(690)\end{array}$ & No or not sure & 69 & 10 \\
\hline $\mathrm{HH}$ willing to purchase & Yes & 448 & 53 \\
\hline ITNs from the market & No & 397 & 47 \\
\hline \multirow[t]{2}{*}{ ITNs washed (690) } & Yes & 292 & 42.3 \\
\hline & No & 398 & 57.7 \\
\hline Washing frequency of & Once a week & 93 & 25.9 \\
\hline \multirow[t]{5}{*}{ ITNs (359) } & Once every 2 weeks & 89 & 24.8 \\
\hline & Once a month & 71 & 19.8 \\
\hline & Once every 3 months & 75 & 20.9 \\
\hline & Once every 6 months & 31 & 8.6 \\
\hline & and above & & \\
\hline Mean price of ITNs & $<40.2$ ETB & 65 & 64.4 \\
\hline purchased by $\mathrm{HH}(|0|)$ & $\geq 40.2$ ETB & 36 & 35.6 \\
\hline Mean ITN price $\mathrm{HH}$ & $<34.6$ ETB & 232 & 54.6 \\
\hline willing to pay (425) & $\geq 34.6 \mathrm{ETB}$ & 193 & 45.4 \\
\hline
\end{tabular}

Abbreviations: $\mathrm{HH}$, household; ITNs, insecticide-treated nets.

among pregnant and children $<5$ years, respectively. Only $15.9 \%$ of the HHs used ITNs consistently.

\section{Factors that influenced ITN use}

As shown in table 7, some sociodemographic variables showed significant differences in ITN use during bivariate analysis after CORs, $95 \% \mathrm{CIs}$, and $P$-values had been
Table 6 ITN utilization, HHs of Itang special district, Gambella region, Ethiopia, 2015

\begin{tabular}{|c|c|c|c|}
\hline Variables & Categories & Frequency & Percentage \\
\hline $\mathrm{HHs}$ with any member of & No & 329 & 47.7 \\
\hline $\begin{array}{l}\text { the family that slept under } \\
\text { any ITN last night }(690)\end{array}$ & Yes & 361 & 52.3 \\
\hline At least one child $<5$ years & Yes & 135 & 56 \\
\hline $\begin{array}{l}\text { slept under ITN last night } \\
(24 I)\end{array}$ & No & 106 & 54 \\
\hline Pregnant women slept & Yes & 94 & 51.4 \\
\hline $\begin{array}{l}\text { under ITNs the night prior } \\
\text { to survey }(183)\end{array}$ & No & 89 & 48.6 \\
\hline \multirow[t]{2}{*}{ Consistent ITN users (690) } & Yes & 110 & 15.9 \\
\hline & No & 580 & 84.1 \\
\hline $\mathrm{HHs}$ that believed they had & Yes & 382 & 45.2 \\
\hline inadequate ITNs & No & 463 & 54.8 \\
\hline $\mathrm{HHs}$ that believed ITNs & Yes & 215 & 25.4 \\
\hline $\begin{array}{l}\text { incompatible with their } \\
\text { sleeping habit }\end{array}$ & No & 630 & 74.6 \\
\hline
\end{tabular}

Abbreviations: $\mathrm{HH}$, households; ITN, insecticide-treated net.

computed to identify levels of significance of ITN use in HHs. HH heads aged 40-49 and 50+ years were 3.11 and 3.07 times respectively, more likely to use ITNs than those aged $<30$ years, with respective COR $(95 \% \mathrm{CI})$ of 3.11 (1.95-4.94) and 3.07 (1.80-5.26). Rural HHs were 1.72 times more likely to use ITNs than urban HHs: COR $(95 \%$ CI) of 1.72 (1.21-2.45). In Table 8, HHs with no knowledge of prevention of malaria comprised $64.3 \%$, and were less likely to use ITNs than their counterparts, with COR $(95 \%$ CI) of $0.36(0.26-0.49)$. Those HHs that did not have IRS for their dwellings for the past 12 months were $38.5 \%$ less likely to use ITNs than their counterparts, with COR $(95 \% \mathrm{CI})$ of $0.615(0.46-0.83)$. HHs who preferred to use conical ITNs were $30 \%$ less likely to use them than those that preferred rectangular ITNs, with COR $(95 \% \mathrm{CI})$ of 0.7 (0.52-0.95). HHs with two and three ITNs were 4.85 and 5.07 times more likely to use ITNs than HHs with only one ITN, with COR (95\% CI) of 4.85 (3.23-7.18) and 5.07 (3.36-7.66).

Among 44 variables studied in bivariate analysis of ITN use in this study (Tables 7 and 8), some showed significant difference with $P$-values of $<0.05$, while in order to avoid missing variables that were significant in other similar studies of the country, a $P$-value $\leq 0.15$ was used as a cutoff point for multivariable analysis. Sixteen variables that were significant at $P \leq 0.15$ were entered for backward-stepwise binary logistic regression, which controlled undesirable effects of confounders between variables and the problem of multicollinearity, and declared true association. Hosmer-Lemeshow goodness-of-fit statistics were checked for fullness of the model. The final model showed 0.886 goodness, very far from 0.05 and clearly indicating the outcome variable was 
Table 7 Bivariate analysis of factors associated with ITN use in Itang special district, Gambella region, Ethiopia, 2015

\begin{tabular}{|c|c|c|c|c|c|c|c|}
\hline \multirow[t]{2}{*}{ Variables } & \multirow[t]{2}{*}{ Categories } & \multicolumn{2}{|c|}{ ITN use } & \multirow[t]{2}{*}{$P$-value } & \multirow[t]{2}{*}{ COR } & \multicolumn{2}{|l|}{$95 \% \mathrm{Cl}$} \\
\hline & & Yes & No & & & Lower & Upper \\
\hline \multirow[t]{4}{*}{ HH-head age } & $<30$ years & 45 & 83 & I & 1 & 1 & $\mathrm{I}$ \\
\hline & $30-39$ years & 128 & 134 & 0.011 & 1.762 & 1.139 & 2.725 \\
\hline & $40-49$ years & 123 & 73 & 0.000002 & 3.108 & 1.954 & 4.944 \\
\hline & 50 years and above & 65 & 39 & 0.00004 & 3.074 & 1.795 & 5.264 \\
\hline $\mathrm{HHs}$ with pregnant & Yes & 94 & 89 & $\mathrm{I}$ & $\mathrm{I}$ & 1 & I \\
\hline women & No & 267 & 240 & 0.763 & 1.053 & 0.751 & 1.477 \\
\hline \multirow[t]{2}{*}{$\mathrm{HH}$ residence } & Urban & 69 & 95 & I & 1 & 1 & 1 \\
\hline & Rural & 292 & 234 & 0.003 & 1.718 & 1.205 & 2.449 \\
\hline \multirow[t]{2}{*}{ HH-head sex } & Female & 71 & 53 & 1 & 1 & I & 1 \\
\hline & Male & 290 & 276 & 0.225 & 0.784 & 0.530 & 1.161 \\
\hline Educational status & Cannot write or read & 90 & 70 & I & I & 1 & I \\
\hline \multirow[t]{4}{*}{ of $\mathrm{HH}$ head } & Able to write and read & 106 & 86 & 0.845 & 0.959 & 0.628 & 1.463 \\
\hline & Elementary level (I-8) & 72 & 54 & 0.880 & 1.037 & 0.647 & 1.661 \\
\hline & High school level (9-12) & 52 & 67 & 0.039 & 0.604 & 0.374 & 0.974 \\
\hline & Higher education completed & $4 I$ & 52 & 0.063 & 0.613 & 0.366 & 1.026 \\
\hline $\mathrm{HH}$-head marital & Single & 13 & 28 & 1 & 1 & I & 1 \\
\hline \multirow[t]{3}{*}{ status } & Married & 302 & 253 & 0.006 & 2.571 & 1.304 & 5.068 \\
\hline & Divorced & 23 & 23 & 0.086 & 2.154 & 0.897 & 5.17 \\
\hline & Widowed & 23 & 25 & 0.123 & 1.982 & 0.832 & 4.72 \\
\hline $\mathrm{HH}$-head & Farmer & 189 & 133 & 1 & 1 & 1 & 1 \\
\hline \multirow{5}{*}{ occupational status } & Fisherman & 52 & 52 & 0.121 & 0.704 & 0.451 & 1.097 \\
\hline & Housewife & 24 & 17 & 0.984 & 0.993 & 0.514 & 1.922 \\
\hline & Merchant & 43 & 52 & 0.021 & 0.582 & 0.367 & 0.923 \\
\hline & Pastoralist & 41 & 52 & 0.013 & 0.555 & 0.348 & 0.884 \\
\hline & Other & 12 & 23 & 0.007 & 0.367 & 0.177 & 0.764 \\
\hline $\mathrm{HHs}$ with children & Yes & 135 & 106 & I & 1 & 1 & 1 \\
\hline aged $<5$ years & No & 226 & 223 & 0.155 & 0.796 & 0.581 & 1.09 \\
\hline \multirow[t]{4}{*}{ Family size } & $\mathrm{I}-2$ & 100 & 57 & I & 1 & 1 & 1 \\
\hline & $3-5$ & 101 & 91 & 0.037 & 0.633 & 0.411 & 0.974 \\
\hline & $6-7$ & 113 & 105 & 0.023 & 0.613 & 0.403 & 0.934 \\
\hline & $\geq 8$ & 47 & 76 & 0.00003 & 0.353 & 0.216 & 0.574 \\
\hline Persons sharing one & $1-2$ & $|5|$ & 42 & 1 & 1 & 1 & 1 \\
\hline \multirow[t]{2}{*}{ bed } & $3-5$ & 130 & 157 & 0.000001 & 0.230 & 0.152 & 0.348 \\
\hline & 6 and above & 80 & 130 & 0.00001 & 0.171 & 0.11 & 0.266 \\
\hline Sleeping rooms & One & 195 & 195 & I & I & 1 & 1 \\
\hline \multirow[t]{2}{*}{ of $\mathrm{HH}$} & Two & 87 & 71 & 0.283 & 1.225 & 0.846 & 1.776 \\
\hline & Three and above & 79 & 63 & 0.251 & 1.254 & 0.852 & 1.845 \\
\hline Adolescent sleeping & Everybody sleeps alone & 82 & 34 & I & I & 1 & 1 \\
\hline \multirow[t]{2}{*}{ pattern (49I) } & All males together or all females together & 69 & 124 & 0.00001 & 0.231 & 0.14 & 0.379 \\
\hline & Both males and females together & 13 & 47 & 0.00001 & 0.115 & 0.055 & 0.239 \\
\hline
\end{tabular}

Abbreviations: $\mathrm{HH}$, household; ITN, insecticide-treated net; COR, crude odds ratio; $\mathrm{Cl}$, confidence interval.

fully explained by the independent variables entered in the full model. The same findings were also obtained with forward-stepwise regression.

Table 9 shows only seven variables remained significant predictors of the outcome variable. HHs without awareness of malaria prevention were $72 \%$ less likely to use ITNs than those with awareness, with AOR $(95 \% \mathrm{CI})$ of 0.28 $(0.15-0.53)$. Bed/sleeping areas shared by three to five and six to seven $\mathrm{HH}$ members were $81 \%$ and $86 \%$ less likely to use ITNs, respectively, than bed/sleeping areas shared by one to two HH members, with AOR $(95 \% \mathrm{CI})$ of 0.19
$(0.1-0.38)$ and $0.14(0.06-0.3)$. HHs with adolescents that had a sleeping pattern of males or females together were $84 \%$ and $92 \%$ less likely to use ITNs than those with adolescents sleeping alone, with AOR $(95 \% \mathrm{CI})$ of $0.16(0.1-0.33)$ and $0.08(0.03-0.19)$ respectively. HHs with two and three ITNs were 4.77 and 4.65 times more likely to use ITNs than HHs with only one ITN, with AOR ( $95 \%$ CI) of 4.77 (2.16-10.52) and 4.65 (2.08-10.4), respectively. HHs with family size of eight and above were $75 \%$ less likely to use ITNs than HHs with family size of one to two, with AOR ( $95 \% \mathrm{CI})$ of 0.25 (0.11-0.59). HHs who felt comfortable with ITNs for family 
Table 8 Bivariate analysis of ITN use related to source of information and condition about ITNs in Itang district, Gambella region, Ethiopia, 2015

\begin{tabular}{|c|c|c|c|c|c|c|c|}
\hline \multirow[t]{2}{*}{ Variables } & \multirow[t]{2}{*}{ Categories } & \multicolumn{2}{|c|}{ ITN use } & \multirow[t]{2}{*}{$P$-value } & \multirow[t]{2}{*}{ COR } & \multicolumn{2}{|l|}{$95 \% \mathrm{Cl}$} \\
\hline & & Yes & No & & & Lower & Upper \\
\hline \multirow[t]{2}{*}{$\mathrm{HH}$ radio possession } & Yes & 155 & 192 & 1 & I & I & $\mathrm{I}$ \\
\hline & No & 206 & 137 & 0.00006 & $\mathrm{I} .863$ & 1.376 & 2.52 \\
\hline $\mathrm{HHs}$ with awareness of malaria & Yes & 273 & 173 & 1 & I & 1 & 1 \\
\hline preventability & No & 88 & 156 & 0.000005 & 0.357 & 0.259 & 0.494 \\
\hline HHs that knew ITNs can & Yes & 248 & 214 & I & I & 1 & 1 \\
\hline prevent malaria & No & 113 & 115 & 0.308 & 0.848 & 0.617 & 1.165 \\
\hline Source of information about & Health staffs & 211 & 129 & I & I & 1 & 1 \\
\hline malaria & CHWs & 62 & 44 & $0.5 \mathrm{II}$ & 0.861 & 0.553 & 1.34 \\
\hline IRS status of house in past 12 & Yes & 205 & 147 & 1 & I & I & I \\
\hline months & No or not sure & 156 & 182 & 0.002 & 0.615 & 0.455 & 0.831 \\
\hline \multirow[t]{3}{*}{ ITNs per HH (690) } & One & 58 & 160 & I & I & 1 & 1 \\
\hline & Two & 167 & 95 & 0.00001 & 4.849 & 3.277 & 7.177 \\
\hline & Three & 136 & 74 & 0.00001 & 5.070 & 3.355 & 7.661 \\
\hline Shape of ITNs HHs prefer & Rectangular & 193 & 147 & 1 & 1 & 1 & 1 \\
\hline to use & Conical & 168 & 182 & 0.021 & 0.703 & 0.521 & 0.949 \\
\hline \multirow[t]{3}{*}{ Color preference of $\mathrm{HHs}$} & Blue & 215 & 165 & 0.043 & I & 1 & I \\
\hline & White & 124 & 142 & 0.013 & 0.670 & 0.489 & 0.918 \\
\hline & Others & 22 & 22 & 0.406 & 0.767 & $0.4 I I$ & 1.433 \\
\hline Duration of ITNs obtained & $<=6$ months & 132 & 97 & 1 & I & I & I \\
\hline \multirow[t]{2}{*}{ (690) } & $1-3$ years ago & 178 & 183 & 0.049 & 0.715 & 0.512 & 0.998 \\
\hline & $3-5$ and above & 51 & 49 & 0.265 & 0.765 & 0.477 & 1.226 \\
\hline Observed condition of ITNs & Good (no holes) & 218 & 248 & I & I & I & $\mathrm{I}$ \\
\hline \multirow[t]{2}{*}{$(690)$} & One thumb hole & 112 & 70 & 0.317 & I.187 & 0.848 & 1.662 \\
\hline & $>$ thumb and $<$ head and more & 31 & 11 & 0.863 & 0.954 & 0.56 & 1.626 \\
\hline $\mathrm{HH}$ s that had ever purchased & Yes & 40 & 63 & 1 & 1 & I & I \\
\hline ITNs & No & 321 & 266 & 0.003 & 1.901 & 1.239 & 2.917 \\
\hline Factory-treated ITNs & Yes & 316 & 305 & 1 & 1 & I & I \\
\hline (HHs that received LLINs) & No or not sure & 45 & 24 & 0.025 & 1.81 & 1.076 & 3.043 \\
\hline HHs willing to purchase ITNs & Yes & 198 & 203 & I & 1 & 1 & I \\
\hline from the market & No & 163 & 126 & 0.069 & 1.326 & 0.979 & $\mathrm{I} .797$ \\
\hline $\mathrm{HHs}$ that believed they had & Yes & 150 & 78 & 1 & 1 & 1 & 1 \\
\hline inadequate ITNs & No & 211 & 251 & 0.000001 & 0.437 & 0.315 & 0.608 \\
\hline $\mathrm{HHs}$ that believed ITNs & Yes & 139 & 263 & 1 & 1 & I & I \\
\hline $\begin{array}{l}\text { incompatible with their } \\
\text { sleeping habits }\end{array}$ & No & 222 & 66 & 0.000001 & 6.364 & 4.516 & 8.97 \\
\hline
\end{tabular}

Abbreviations: $\mathrm{HH}$, household; ITN, insecticide-treated net; COR, crude odds ratio; $\mathrm{Cl}$, confidence interval; IRS, indoor residual spray; $\mathrm{CHWs,} \mathrm{community} \mathrm{health} \mathrm{workers;}$ LLINs, long-lasting insecticide-treated nets.

sleeping habits were 4.55 times more likely to use ITNs than their counterparts, with AOR (95\% CI) of 4.55 (2.53-8.19). HHs headed by those aged 40-49 and 50+ years were 2.84 and 4.14 times more likely to use ITNs than those headed by those aged $<30$ years, with AOR (95\% CI) of 2.84 (1.17-6.89) and 4.14 (1.52-11.27).

\section{Discussion}

In this study, a $100 \%$ respondent rate was achieved. The reason for this might have been the wide range of inclusion criteria of this study, favored by data-collection period when most adult family members were free from agricultural activities. As a result of ensuring the reliability of data, the collection period for data was scheduled in the early morning.
This provided a double benefit for this study, as the timing allowed a high response rate.

This study showed more than three-quarters of the studied HHs had at least one ITN, while nearly half the HHs used at least one of their ITNs by the night prior to the survey. Less than a quarter used the ITNs regularly without any interruption. ITN ownership seemed higher than that of most study results of the country, but the $95 \%$ CI was $78.6 \%-84.1 \%$, which was not so different from other study findings for the country, such as those conducted in Kersa and Gursum districts and East Welega, which revealed $65.5 \%, 62.4 \%$, and $69.3 \%$, respectively. ${ }^{10,15,16}$ The study conducted in the Kersa district of Eastern Ethiopia came up without much difference between urban (72\%) and 
Table 9 Final model of multivariable analysis for factors associated with use of ITNs in Itang district, Gambella region, Ethiopia, 2015

\begin{tabular}{|c|c|c|c|c|c|}
\hline \multirow[t]{2}{*}{ Variables } & \multirow[t]{2}{*}{ Categories } & \multicolumn{2}{|c|}{ ITN use } & \multirow[t]{2}{*}{ COR $(95 \% \mathrm{Cl})$} & \multirow[t]{2}{*}{ AOR (95\% CI) } \\
\hline & & $\overline{\text { Yes }}$ & No & & \\
\hline $\mathrm{HHs}$ with awareness of & Yes & 273 & 173 & 1 & 1 \\
\hline malaria preventability & No & 88 & 156 & $0.36(0.26-0.49) * * *$ & $0.28(0.15-0.53)^{* * *}$ \\
\hline \multirow[t]{3}{*}{ Persons sharing one bed } & $\mathrm{I}-2$ & $15 \mid$ & 42 & I & I \\
\hline & $3-5$ & 130 & 157 & $0.23(0.15-0.35)^{* * *}$ & $0.19(0.1-0.38)^{* * *}$ \\
\hline & 6-7 and 8+ & 80 & 130 & $0.17(0.11-0.27)^{* * *}$ & $0.14(0.06-0.3)^{* * *}$ \\
\hline Sleeping pattern of adolescents & Everybody sleeps alone & 82 & 34 & I & 1 \\
\hline \multirow[t]{2}{*}{ in the $\mathrm{HH}(49 \mathrm{I})$} & $\begin{array}{l}\text { All males together or all } \\
\text { females together }\end{array}$ & 69 & 124 & $0.23(0.14-0.38)^{* * *}$ & $0.16(0.1-0.33)^{* * * *}$ \\
\hline & $\begin{array}{l}\text { Both males and females } \\
\text { together }\end{array}$ & 13 & 47 & $0.12(0.06-0.24)^{* * *}$ & $0.08(0.03-0.19)^{* * *}$ \\
\hline \multirow[t]{3}{*}{ Number of ITNs per HH (690) } & One & 58 & 160 & 1 & 1 \\
\hline & Two & 167 & 95 & $4.85(3.28-7.28)^{* * *}$ & $4.77(2.16-10.52)^{* * *}$ \\
\hline & Three & 136 & 74 & $5.07(3.56-7.66)^{* * *}$ & $4.65(2.08-10.4)^{* * *}$ \\
\hline \multirow[t]{4}{*}{ Family size } & $\mathrm{I}-2$ & 100 & 57 & 1 & 1 \\
\hline & $3-5$ & 101 & 91 & $0.63(0.4 \mathrm{I}-0.97)^{*}$ & $0.72(0.33-1.59)$ \\
\hline & $6-7$ & 113 & 105 & $0.61(0.4-0.93)^{*}$ & $0.60(0.28-1.25)$ \\
\hline & 8 and above & 47 & 76 & $0.35(0.22-0.57)^{* * *}$ & $0.25(0.11-0.59)^{* *}$ \\
\hline HHs that believed ITNs incompatible & Yes & 139 & 263 & I & $\mathrm{I}$ \\
\hline \multicolumn{6}{|l|}{ sleeping habits } \\
\hline \multirow[t]{4}{*}{ HH-head age } & $<30$ years & 45 & 83 & 1 & 1 \\
\hline & $30-39$ years & 128 & 134 & $1.76(1.14-2.73)^{*}$ & $2.212(0.96-5.1)$ \\
\hline & $40-49$ years & 123 & 73 & $3.11(1.95-4.94)^{* * * *}$ & $2.84(1.17-6.89)^{*}$ \\
\hline & 50 years and above & 65 & 39 & $3.07(1.8-5.26)^{* * * *}$ & $4.14(1.52-11.27)^{* *}$ \\
\hline
\end{tabular}

Notes: $* P<0.05 ; * * P<0.01 ; * * * P<0.001$.

Abbreviations: $\mathrm{HHs}$, households; ITNs, insecticide-treated nets; $\mathrm{COR}$, crude odds ratio; $\mathrm{Cl}$, confidence interval; $\mathrm{AOR}$, adjusted OR.

rural $(64.65 \%)$, where $33.5 \%$ used at least one ITN per HH. ${ }^{10}$ Another study conducted in the Arbaminch Zuria district came up with $58.8 \%$ where at least one ITN, with a higher proportion in rural (73.7\%) than urban (43.3\%) and $82.7 \%$ using at least one ITN. ${ }^{4}$ Another comparative study conducted in Southwest Ethiopia reported 66.3\% with ownership of at least one ITN. ${ }^{18}$ A study conducted in Southeastern Benin reported $88.96 \%$ owned at least one ITN and $84 \%$ used at least one ITN. ${ }^{13}$

However, in the study area, ITN ownership was far from the 2015 universal-coverage target of the country of the RBM, which was declared by African leaders in 2000 at Abuja. ${ }^{8}$ From total studied $\mathrm{HHs}$, less than a quarter of HHs were fully covered by ITNs. According to the RBM target, HHs with six or seven family members required three ITNs. Therefore, in this study area, nearly half of the HHs required three or more ITNs. In spite of this, there is no significant difference in the utilization proportion of ITNs among universally covered and uncovered HHs, which amounted to $51.2 \%$. The reason for this may be that most of the HHs of the studied area had single sleeping houses/rooms that were not spacious enough to hang up all the ITNs available in the HH. There is also the habit of most $\mathrm{HH}$ members sharing one bed or sleeping area, while the ITNs delivered to the population were not plentiful enough to accommodate all family members' sleeping habits. In addition to this, the design of their huts (conical with high ceiling) renders them impractical to hang up nets of any shape currently distributed through the distribution schemes of the country.

The observation of a hanging ITN above a bed or sleeping place by the enumerators and the $\mathrm{HH}$ response of any of their family members who slept under any ITN was considered utilization. The use of any ITN of the surveyed HH was lower compared to other study findings conducted in the country. This may have been due to this cross-sectional study being conducted during the dry season of the area, with no other mosquito nuisance, even though malaria transmission is stable throughout the year. In this study, there was a higher proportion of HH ITNs owned by rural than urban residents, which is similar to a study conducted in Arbaminch Zuria district, which was contrary to a study conducted in Eastern Ethiopia. ${ }^{3,10}$ The reason for this may be attributed to distribution of all ITNs through the district health office distribution scheme, which gave more emphasis to rural residents than urban. Related to this, ITNs are not easily accessible in the local market of the area. 
Predictive factors for ITN use in this study were respondent awareness of malaria prevention, number of family members sharing a bed/sleeping area, adolescent family members' sleeping patterns, number of ITNs in the HH, HH family size, ITN incompatibility with family sleeping habits, and HH-head age. Similarly, in research conducted in Kersa in Eastern Ethiopia, the number of ITNs owned per HH was the predictor of ITN use. HHs with one or two ITNs were $75 \%$ and $67 \%$ less likely to use ITNs than those with three or more ITNs, with AOR ( $95 \% \mathrm{CI})$ of $0.25(0.17-0.39)$ and $0.36(0.25-0.54)$, and also awareness of respondents about malaria prevention was a significant predictor of ITN use. Whereas, this significant association shown among not having any awareness and not knowing whether it can prevent or not, with AOR $(95 \% \mathrm{CI})$ of $0.43(0.27-0.68)$, while unlike the East Ethiopia study finding, ITN-color preference and $\mathrm{HH}$ residing in rural and urban areas were significant in the initial phase of bivariate analysis, but not significant when confounders were controlled. ${ }^{10}$

Contrary to a study conducted in Southwest Ethiopia in 2013, this study revealed that when the age of the HH head increases, the use of ITNs most likely also increased, while the Southwest Ethiopia study showed when HH-head age increases the use of ITNs most likely declined..$^{18}$ In Southwest Ethiopia, HH heads aged between $<30$ years and 30 -49 years were three times and twice as likely to use ITNs than those aged 60 years, respectively. In this study, ITN utilization increased as HH-head age increased (Table 8). The reason for this could be that advanced age makes people much more exposed and prone to malaria than younger people. Often, those aged $<40$ years are risk takers and might not take care of their own and their families' health, as their concentration is more on business and creative activities. On the other hand, similar to this study, family size was also an important predictor for ITN use in Southwest Ethiopia: HHs with a family size one to three were 1.7 times more likely to use ITNs than those with seven or more. ${ }^{18}$ The reason for this could be increased space and sleeping rooms, even though they have an adequate number of ITNs for the size of the family.

In most of the literature, wealth was revealed as a decisive factor of ITN use, but in this study there was no significant association. This could be due to the fact that in this study, only HH-head income was assessed, not incomes of other family members, and thus most of the HHs had more or less similar livelihood and lifestyle. However, unlike other study findings, sleeping patterns of adolescents and number of family members sharing one bed/sleeping area were significant predictive factors for ITN use in this study area. The Kersa study showed that HHs that shared one bed provided a good opportunity for young children to sleep under ITNs available in the HH. ${ }^{10}$ The reason for this may be that in this study area, more than half of the HHs had a single living room and the design of their houses, which was not spacious enough to allow for separate beds/ sleeping areas for the family. Even the observation report of this study showed that most ITNs were hung outside the living room on the fence and exposed to direct sunlight during the day, because of a lack of storage space. In this case the problem of insecticide integrities and life span of ITN could ultimately be questionable. Apart from this, other reasons for adolescent sleeping habits, which appeared to be a significant factor in this study, might have been some ethnic groups of the study-area population, for whom adolescents sharing a bed with their parents is forbidden, which might persuade the $\mathrm{HH}$ to have more than one sleeping area in the room and thereby not have ITNs covering all family members.

Slightly more than half of the respondents were willing to buy ITNs if they were available at an affordable price. The mean affordable price revealed by study participants was 34.6 ETB. Affordability varies from $\mathrm{HH}$ to $\mathrm{HH}$, depending on income and awareness of ITNs as a preventive measure against malaria and other insect bites. The intention of the respondents toward buying ITNs will be an alarming situation for those stakeholders who are working in this study area to think about social marketing principles of ITN distribution. Social marketing as one option for ITN distribution may play a great role in increasing $\mathrm{HH}$ ownership, and it might be promoted more as long as the scheme creates reasonable business for distributors and promoters.

With regard to consistent utilization of ITNs, this study found very low use. Below one quarter of HH use ITN consistently among HHs that had one or more ITNs and at least one $\mathrm{HH}$ member had slept under a net the night prior to the survey. This finding was much lower than that of Gida Ayana, where $51 \%$ consistently used ITNs, and was much lower than the Arbaminch Zuria study, at 71\%.,15 It seems that consistent use of ITNs in this study area is extremely low in comparison to the RBM target of $80 \%$ consistent use by the year $2015{ }^{6,8}$ This shows most of the HH members of the study area had a high risk of person-to-mosquito contact, due to lack of barriers and knockdown effect of ITNs. This situation clearly shows that the populations under study had higher exposure to mosquito bites. Consequently, inconsistent utilization of ITNs may be the main reason for a higher risk 
of malaria. The reason for not using ITNs in a consistent manner could be a lack of compatibility of HHs that owned ITNs in relation to family sleeping habits, as well as other socioeconomic factors of the study area. This study was limited to in-depth interviews and focus-group discussions to explore and focus on what motivates people and factors that hinder consistent use of ITNs.

\section{Conclusion}

ITN ownership in this study area was low and is not in line with family size or the RBM target of ownership. The proportion of HHs reporting at least one family member sleeping under an ITN the night prior to the survey was below average and below half the RBM or country target of 2015. The consistent-utilization report of this study was poorest when compared to RBM and country targets of consistent ITN use. The RBM target was seated to have ITN herd effect on mosquito population reduction and on the reduction of risk of malaria through its barrier and knockdown effect. Therefore, study-area populations were at higher risk of mosquito bites and acquiring malaria and other vector-borne diseases that can be prevented by higher utilization of ITNs. This study also showed barriers to ITN use among the study population. According to this research, the use of ITNs is affected by sociodemographic, individual, and ITN-related factors.

Therefore, these situations clearly indicate that Federal Ministry of Health and other partners involved on ITN promotion and distribution should work on finding innovative solutions that consider the best way to fit ITNs in small houses. Federal Ministry of Health should specifically target those HHs with a bigger family size and those sharing one bed, in order to provide bigger ITNs that could accommodate HH members. District health offices should work intensively on promoting ITNs and increasing HH ownership, in order to maximize their use, and regional health bureaus and district health offices should consider social marketing principles of ITN distribution to increase ownership, as well as sustainability.

\section{Author contributions}

All authors contributed toward data analysis, drafting and revising the paper and agree to be accountable for all aspects of the work.

\section{Acknowledgments}

The authors would like to give their gratitude to those who participated in data enumeration and the supervisors of the data-collection process. They would like to say thanks to the Itang Special District Health Office head and all other staff for their valuable information on preliminary conditions of this study area.

\section{Disclosure}

The authors report no conflicts of interest in this work.

\section{References}

1. Pinder M, Jawara M, Jarju L, et al. To assess whether indoor residual spraying can provide additional protection against clinical malaria over current best practice of long-lasting insecticidal mosquito nets in the Gambia: study protocol for a two-armed cluster-randomised trial. Trials. 2011;12:147.

2. World Health Organization. World Malaria Report 2014. Geneva: WHO; 2014. Available from: http://www.who.int/malaria/publications/ world_malaria_report_2014/report/en. Accessed April 14, 2016.

3. Astatkie A, Feleke A. Utilization of insecticide treated nets in Arbaminch town and the malarias villages of Arbaminch Zuria district, southern Ethiopia. Ethiop J Health Dev. 2009;23:206-215.

4. Gebre B, Negash Y. Severe malaria among children in Gambella, western Ethiopia. Ethiop J Health Dev. 2002;16:61-70.

5. Hamat BJ, Osman B. A promising role of insecticide treated bednets (ITNs) against malaria: a way forward. J Nat Sci Res. 2012;2: 91-101.

6. Woyessa A, Deressa W, Ali A, Lindtjørn B. Ownership and use of long-lasting insecticidal nets for malaria prevention in Butajira area, south-central Ethiopia: complex samples data analysis. BMC Public Health. 2014;14:99.

7. Hwang J, Patterson J, Ashton R, et al. Ethiopia National Malaria Indicator Survey 2011. Addis Ababa: Ethiopian Health Nutrition Research Institute; 2012.

8. Federal Democratic Republic of Ethiopia. National Malaria Guideline of 2012. Addis Ababa: FMOH, 2012. Availlable from: www.medbox.org/ national-malaria-guidelines-ethiopia/download.pdf. Accessed May 1, 2016.

9. Asseged S. Household illness prevalence and its determinants among under five children in Gambella special woreda, south east Ethiopia [master's thesis]. School of Graduate Studies of Addis Ababa University. 2006.

10. Gobena T, Berhane Y, Worku A. Low long-lasting insecticide nets (ITNS) use among household members for protection against mosquito bite in Kersa, eastern Ethiopia. BMC Public Health. 2012;12:914.

11. Bekele D, Berhane Y, Petros B, Deressa W. Assessment of the effect of insecticide-treated nets and indoor residual spraying for malaria control in three rural kebeles of Adami Tulu district, south central Ethiopia. Malar J. 2012;11:127.

12. Azondekon R, Gnanguenon V, Oke-Agbo F, Houevoessa S, Green M, Akogbeto M. A tracking tool for long-lasting insecticidal (mosquito) net intervention following a 2011 national distribution in Benin. Parasit Vectors. 2014;7:6.

13. Tokponnon F, Sissinto Y, Ogouyémi A, et al. Assessment of long-lasting insecticidal net coverage, use and physical integrity one year after universal distribution campaign in plateau department in south-east Benin. J Public Health Epidemiol. 2014;6:76-84.

14. Biadgilign S, Reda A, Kedir H. Determinants of ownership and utilization of insecticide-treated bed nets for malaria control in eastern Ethiopia. J Trop Med. 2012;2012:235015.

15. Tadele G, Samuel A, Adeba E. Replacement of long lasting insecticide treated nets in malarious kebeles of Gida Ayana district, East Wollega zone, Ethiopia. Sci Technol Arts Res J. 2014;3:162-166.

16. Fullman N, Burstein, R, Lim S, Medlin C, Gakidou E. Nets, spray or both? The effectiveness of insecticide-treated nets and indoor residual spraying in reducing malaria morbidity and child mortality in subSaharan Africa. Malar J. 2013;12:62. 
17. Kumie A, Felema B. Assessment of insecticide treated nets (ITNs) utilization among children under five years of age and pregnant women of Adama woreda, Oromia regional state, Ethiopia. Community health department of Addis Ababa university master's in public health program. 2008. Available from: http:/etd.aau.edu.et/handle/123456789/3133. Accessed April 14, 2016.

18. Sena L, Wakgari A, Ali A. Predictors of long-lasting, insecticide-treated, bed net ownership and utilization: evidence from community-based crosssectional comparative study, southwest Ethiopia. Malar J. 2013;12:406.

19. Legesse Y, Tegegn A, Belachew T, Tushune K. Knowledge, attitude and practice about malaria transmission and its preventive measures among households in urban areas of Assosa zone, western Ethiopia. Ethiop J Health Dev. 2007;21:157-165.

20. Berie Y, Alemu K, Belay A, Gizaw Z. Factors affecting utilization of insecticide treated nets among people living with HIV/AIDS in Bahir Dar city, northwest Ethiopia. Sci J Clin Med. 2013;2:147-152.

21. Ruhago G, Mujinja P, Norheim O. Equity implications of coverage and use of insecticide treated nets distributed for free or with co-payment in two districts in Tanzania: a cross-sectional comparative household survey. Int J Equity Health. 2011;10:29.
22. Animut A, Gebre-Michael T, Medhin G, Balkew M, Bashaye S, Seyoum A. Assessment of distribution, knowledge and utilization of insecticide treated nets in selected malaria prone areas of Ethiopia. Ethiop J Health Dev. 2008;22:268-274.

23. Ngufor C, Tungu P, Malima R, Kirby M, Kisinza W, Rowland M. Insecticide-treated net wall hangings for malaria vector control: an experimental hut study in north-eastern Tanzania. Malar J. 2014; $13: 366$.

24. Fettene M, Balkewm, Gimblet C. Utilization, retention and bio-efficacy studies of PermaNet in selected villages in Buie and Fentalie districts of Ethiopia. Malar J. 2009;8:114.

25. World Health Organization. Malaria Vector Control and Personal Protection. Geneva: WHO; 2006.

26. Kimbi H, Nkesa S, Ndamukong-Nyanga J, Sumbele I, Atashili J, Atanga M. Socio-demographic factors influencing the ownership and utilization of insecticide-treated bed nets among malaria vulnerable groups in the Buea Health District, Cameroon. BMC Res Notes. 2014;7:624.

27. Skovmand $O$. Insecticidal bed nets for the fight against malaria - present time and near future. Open Biol J. 2010;3:92-96.
Risk Management and Healthcare Policy

\section{Publish your work in this journal}

Risk Management and Healthcare Policy is an international, peer-reviewed, open access journal focusing on all aspects of public health, policy, and preventative measures to promote good health and improve morbidity and mortality in the population. The journal welcomes submitted papers covering original research, basic science, clinical and epidemiological
Dovepress

studies, reviews and evaluations, guidelines, expert opinion and commentary, case reports and extended reports. The manuscript management system is completely online and includes a very quick and fair peerreview system, which is all easy to use. Visit http://www.dovepress.com/ testimonials.php to read real quotes from published authors. 